\title{
Vector analysis theory on landscape pattern (VATLP) Shuqing
} Zhang $^{\text {a,*, Junyan Zhanga }}$, Fang Li ${ }^{\mathrm{a}}$, Roger Cropp ${ }^{\mathrm{b}}$

\author{
${ }^{a}$ Northeast institute of Geography and Agricultural Ecology, Chinese Academy of Sciences, \\ 5 \\ Changchun, China 130012; \\ ${ }^{\mathrm{b}}$ Faculty of Environmental Science, Griffith University, Nathan, Queensland, Australia, \\ 4111.
}

*Corresponding author (Tel: 86431 5542230; Fax: 86431 5542289; e-mail:

shqzhang@263.net)

10

Abstract

Landscape indices are popular for the quantification of landscape pattern. However, all landscape indices being used so far are scalar quantities, and measure patterns without considering sufficiently the pattern shape and the directionality 15 together. Based on planar characteristics defined in mechanics such as centroid, moment of inertia, product of inertia and principal axes, vector analysis theory on landscape pattern $(V A T L P)$ is explored here. Firstly we establish a coordinate system of centroidal principal axes $(C S C A P)$. Three related new indices including those describing the direction of pattern distribution (patch orientation $(P O)$, vectorial 20 patch orientation $(V P O)$ ), and that indicating the shape of patch's equivalent ellipse (eccentric rate $(E R))$ are deduced. These landscape metrics are then applied to the pattern analysis of the lakes in Qian-an county (the study area), Jilin province, China. The vector-based data sets of the study area come from the National Land Use/Cover Database (NLUCD). The application of the theory help us better 25 understand the pattern formation of the lakes and the related ecological processes that occur on both ends of the major principal axis, e.g., the transportation of energy and materials flow, and the ecological gradients.

Key words: landscape pattern indices, pattern index, pattern analysis theory, mechanics, lake, 30 VATLP

1. Introduction 
Landscape pattern, in general, can be defined as the variability (composition) and arrangement (spatial structure) of phenomena in space (Turner, 1989; Bailey 35and Gatrell, 1995; Csillag and Kabos, 2002), and is a primary focus of landscape ecology (Forman and Godron, 1986; Krummel et al., 1987; Ambrose and Bratton, 1990; Gustafson and Parker, 1992; Chen et al., 2002). Landscape pattern is important because there are strong links between ecological pattern and ecological function and process (Gustafson, 1998). Landscape pattern analysis has received increasing 40 attention in ecological research and the management community (Lehmkuhl and Ruggiero, 1991; Lehmkuhl et al., 1994; Cissel et al., 1999; Hessburg et al., 1999).

Landscape patterns are quantified by landscape pattern indices (LPIs) (Tischendorf, 2001). A large number of LPIs may now be found in the literature (e.g., O’Neill et al., 1988; Turner and Gardner, 1991; Riitters et al., 1995; Haines45 Young and Chopping, 1996; O’Neill et al., 1999). They are developed, according to Li and Archer (1997), variously from statistical measures of dispersion (Pielou, 1977), information theory (O’Neill et al., 1988), fractal geometry (Krummel et al., 1987; Milne, 1992; Plotnick et al., 1993) and percolation theory (Gardner and O’Neill, 1991; Gardner et al., 1993; Li et al., 1996). Most of these indices have been 50 incorporated into landscape analysis packages such as 'r.le' and 'FRAGSTATS' (Baker and Cai, 1992; McCarigal and Marks, 1995; McCarigal et al., 2002).

LPIs have become increasingly popular for quantifying and characterizing various aspects of observed spatial patterns (e.g., Trani and Giles, 1999; Imbernon 55 and Branthomme, 2001; Li et al., 2001). However, indices often need to be interpreted in combination with each other (Riitters et al., 1995; Haines-Young and Chopping, 1996; McCarigal et al., 2002; Tischendorf, 2001), and many of them have substantial deficiencies when used to infer ecological function (Corry and Nassauer. 2005). Some LPIs provide ambiguous information about spatial patterns, I.e. One 60landscape index may have the same numerical value for different spatial patterns (Gustafson and Parker, 1992; Tischendorf, 2001), and several visually different landscapes may exhibit similar LPI values (Remmel and Csillag, 2003). For example, most shape indices (including many fractal methods) use a perimeter-area relationship (Forman and Godron, 1986; Milne, 1991; Riitters et al., 1995; 65 Gustafson, 1998), which may result in the uncertainty of shape identification due to the ignorance of distributive differences in various directions within the patch.

Anisotropy is often found in ecological data because spatial patterns are sometimes produced by directional geophysical phenomena (Legendre and Fortin, 1989; Rossi, 1992; Gustafson, 1998; Wu, 2000). Anisotropy is a key ecological 70 phenomenon (Fu et al., 2001), and may appear in natural or man-made landscapes due to the effects of forces such as wind, fire, flood and tectonics. Patch orientation may also be evident in stable environments such as sheltered bays, with a number of reports of seagrass patches having a consistent orientation (Tanner, 2003). Patches 
with different orientations may have different ecological functions. For instance, the 75 mean and total number of nesting species, and nest abundances for migratory birds can be significantly associated with patch orientation (Gutzwiller, 1992). For many landscapes and research questions then, LPIs that incorporate directionality measures may be helpful for better understanding effects of processes on landscape patterns. Dorner et al. (2002) offers some indices to capture the directionality of patches 80 formed by physiographic gradients. However, indices which are generally adaptive to the analysis of anisotropy have not appeared yet.

In this paper, we propose vector analysis theory on landscape pattern (VATLP). VATLP is unique in that it can describe the pattern shape and its direction simultaneously. VATLP theory is based on the concepts of centroid and principal axes 85 of a shape in mechanics. The new indices are developed from mechanics theory and then applied to the landscape analysis of the lakes in Qian-an county.

\section{Method}

The exploration of VATLP begins with the establishment of a coordinate system for a patch. Three related landscape indices are then developed. The algorithms 90described here are designed to work with data in vector-based systems, but most of the concepts could be easily implemented in raster format. Our spatial analyses use standard routines provided with MapObject 2.0 (Environmental System Research Institute, Redlands, CA), augmented with custom modules written in $\mathrm{C}++$ to conform to MapObject interface specifications. The source code and data mentioned 95 are available from the corresponding author on request.

Pattern properties deduced from mechanics The establishment of VATLP is based on some related definitions in mechanics. A brief review of these definitions, adapted from Timoshenko and Gere (1978), is given below.

The centroid of a patch is a point whose position is defined as the ratio of the 100 moment of area to the total area. The moment of an area is defined as the integral of the distance from axis about which the moment is being calculated, where the integration is carried out over the area. The moment of inertia is defined as the integral of the square distance from axis about which the moment of inertia is being calculated, where the integration is carried out over the area. Product of inertia is

105 defined as the integral of the product of distances from each axis, where the integration is carried out over the area.

Here let S (Fig. 1) be a patch consisting of the boundary and its interior, and its area is $A .(x, y)$ is a point within the polygon. The $x$ and $y$ axes are defined in accordance with the convenient mapping co-ordinates (e.g., the earth coordinate 110 system). Then the moment about the $x$-axis $\left(Q_{\mathrm{x}}\right)$, the moment about $y$-axis $\left(Q_{\mathrm{y}}\right)$, the 
moment of inertia about the $x$-axis $\left(I_{\mathrm{xx}}\right)$, the moment of inertia about the $y$-axis $\left(I_{\mathrm{yy}}\right)$, the product of inertia $\left(I_{\mathrm{xy}}\right)$, and the centroid $(\bar{x}, \bar{y} \quad$ ) of the polygon are given by equations 1-6 respectively. In these equations, any two adjacent points within the boundary (a total of $n$ points) are denoted by $\left(x_{i}, y_{i}\right)$ and $\left(x_{i+1}, y_{i+1} \quad\right)$. (Note, some equations

115 are deduced by applying Green's theorem which relates the value of a line integral to that of a double integral.)

$$
\begin{aligned}
& Q_{x}=-\frac{1}{6} \sum_{i=0}^{n}\left(x_{i+1}-x_{i}\right)\left(y_{i}^{2}+y_{i} y_{i+1}+y_{i+1}^{2}\right) \\
& Q_{y}=-\frac{1}{6} \sum_{i=0}^{n}\left(y_{i+1}-y_{i}\right)\left(x_{i}^{2}+x_{i} x_{i+1}+x_{i+1}^{2}\right) \\
& I_{x x}=-\frac{1}{12} \sum_{i=0}^{n}\left(x_{i+1}-x_{i}\right)\left(y_{i}^{3}+y_{i}^{2} y_{i+1}+y_{i} y_{i+1}^{2}+y_{i+1}^{3}\right)
\end{aligned}
$$

$120 I_{y y}=-\frac{1}{12} \sum_{i=0}^{n}\left(y_{i+1}-y_{i}\right)\left(x_{i}^{3}+x_{i}^{2} x_{i+1}+x_{i} x_{i+1}^{2}+x_{i+1}^{3}\right)$

$$
\begin{aligned}
& I_{x y}=\frac{1}{24} \sum_{i=0}^{n}\left(x_{i}-x_{i+1}\right)\left\{x_{i+1}\left(3 y_{i+1}^{2}+2 y_{i} y_{i+1}+y_{i}^{2}\right)+x_{i}\left(3 y_{i}^{2}+2 y_{i} y_{i+1}+y_{i+1}^{2}\right)\right\} \\
& \bar{x}=\frac{\mathrm{Q}_{\mathrm{y}}}{A}, \quad \bar{y}=\frac{\mathrm{Q}_{\mathrm{x}}}{A}
\end{aligned}
$$

The angle $(\theta)$ between a principal axis and the horizontal axis (Fig. 2), the larger principal moment of inertia $\left(I_{1}\right)$, and the smaller moment of inertia about the principal 125 axes $\left(I_{2}\right)$, can be calculated from equations 7 and 8 :

$$
\tan 2 \theta=\frac{2 I_{x y}}{I_{x x}-I_{y y}} \quad I_{1,2}=\frac{I_{x x}+I_{y y}}{2} \pm \sqrt{\left(\frac{I_{x x}-I_{y y}{ }^{2}}{2}\right)+I_{x y}^{2}}
$$

Principal axes bear the following three properties: (1) the principal axes

are a pair of orthogonal axes having an orientation defined by the angle ( $\theta$ ) (Eq. 7); (2) the product of inertia is zero for the principal axes; and (3) the moment of inertia 130 with respect to one of the principal axes is a maximum (the axis is defined as minor principal axis here) and with respect to the other it is a minimum (this is called major principal axis here).

The principal axis defined by angle $\theta$ from Eq. 7 can either be the major principal 
axis or the minor principal axis, however, the major and minor principal axis can be easily 135 distinguished according to the principal axes' properties mentioned above, and the principal axis defined by angle $\theta$ will be fixed. The anti-clockwise angle ( ${ }^{\alpha}$ in Fig. 2) between the major principal axis and the horizontal line is determined as follows:

If the major principal axis is defined by $\theta$, then $P O=\theta$; otherwise, $\theta$ is the angle between the horizontal line and the minor principal axis. In this case, if $\theta>\frac{\pi}{2} \quad, P O=\theta$ $140 \frac{\pi}{2}$, else $P O=\theta+\frac{\pi}{2} \quad$ (Fig. 2)

\section{Coordinate system of centroidal principal axis (CSCPA)}

In order to carry out a vectorized analysis on landscape pattern quantitatively, a coordinate system of centroidal principal axes $(C S C A P)$ is designed by designating the centroid of a patch as the origin of CSCAP, the major principal axis as the $x$-axis,

145 and the minor principal axis as the $y$-axis. CSCAP can be gained by panning the related earth coordinate system to the centroid of the patch and then rotating the coordinate system to the principal axes. The axial directions are defined based on the areal differences distributed on both sides of the minor principal axis. Generally speaking, the areas of both parts of the patch separated by minor principal axis are 150not equal, and the length of the major principal axis in the lesser area side is longer than that in the larger area side (Timoshenko and Gere, 1978). The patch will be cuneiform (raindrop) shaped, from the larger area side to the less area side along the major principal axis I.e., $x$-axis. The positive direction of $x$-axis is designed to be in the less area side here. Once the positive direction of $x$-axis is made certain, the other 155 axial directions of CSCAP are determined.

New Indices

Indices of patch orientation and vectorized patch orientation (PO/VPO) Based on the coordinate system of CSCAP, indices of patch orientation $(P O)$ and vectorized patch orientation $(V P O)$ are derived. $P O\left(0 \leq P O \leq 180^{\circ}\right)$ is the orientation of major 160principal axis (I.e. $x$-axis) of the patch, which is defined by the anti-clockwise angle between the horizontal line and the major principal axis (i.e. angle ${ }^{\alpha}$ in Fig. 2) calculated from above mentioned method.

The index of vectorized patch orientation $(V P O)\left(0 \leq V P O \leq 360^{\circ}\right)$, not only calculates the patch orientation with index $P O$, but also defines the positive direction 
165 of patch orientation in accordance with the positive direction of $x$-axis in order to reflect the cuneiform property of the patch. So $V P O$ ( $\beta$ in Fig. 2$)$ is the anticlockwise angle between the horizontal line and the positive direction of $x$-axis.

Generally, when the areas on each side of the minor principal axis of a patch are equal the orientation of the patch $(P O)$ is clearly attained, but when this is the case, 170 VPO is not useful because the patch has little anisotropy on the major principal axis. These patches are called "non-positively oriented patches (NPOP)". This implies we need to measure the ratio of the areas - if this is near 1, VPO is useless. We could then put some condition on this, I.e., if $\left|1-\frac{A_{1}}{A_{2}}\right| \geq \varepsilon \quad,(0<\varepsilon \quad<1)$ (where $A_{1}$ and $A_{2}$ are the areas on each side of the minor principal axis of a patch and ${ }^{\mathcal{E}} \quad$ is a small

175 fuzzy value that determines a minimum level of anisotropy for the analysis). If this condition holds, the measurement of positive directionality is useful, and then the patches are called "positively oriented patches (POP)".

\section{Index of eccentric rate $(E R)$}

In order to quantify the shape of a patch, an equivalent ellipse $\left(E^{r}\right)$ with semi180 major and semi-minor axes $\left(a_{r}, b_{r}\right)$, is proposed such that the area of $\mathrm{E}^{\mathrm{r}}$ is equal to $A$ (the area of patch $\mathrm{S})$. Another ellipse with semi-major and semi-minor axes ( $a_{s}$, $b_{s} \quad$ ), called the regarding equivalent ellipse $\left(\mathrm{E}^{\mathrm{s}}\right)$, is also designed such that the moments of inertia about major and minor axes of $E^{s}$ are equivalent to those of the patch. Both ellipses have the same centroid as that of the patch, and the major axes 185 and the minor axes of both ellipses are on the major principal axis and the minor principal axis of the patch respectively. The positional relationship among the patch $\mathrm{S}$, ellipse $\mathrm{E}^{\mathrm{r}}$ and ellipse $\mathrm{E}^{\mathrm{s}}$ is shown by Fig. 3, where $C$ is the centroid, and $M N$ and $P Q$ are major principal axis and minor principal axis of the patch respectively. The properties of the ellipses are:

$$
\begin{aligned}
& s_{r}=\pi \cdot a_{r} b_{r}, \\
& s_{s}=\pi \cdot a_{s} b_{s}, \\
& I_{x}^{s}=\frac{\pi}{4} a_{s} b_{s}^{3},
\end{aligned}
$$




$$
\begin{gathered}
I_{y}^{s}=\frac{\pi}{4} a_{s}^{3} b_{s}, \\
I_{x}^{r}=\frac{\pi}{4} a_{r} b_{r}^{3}, \\
I_{y}^{r}=\frac{\pi}{4} a_{r}^{3} b_{r}, \\
\frac{I_{x}^{s}}{I_{y}^{s}}=\frac{I_{x}^{r}}{I_{y}^{r}},
\end{gathered}
$$

where $s_{r}$ is the area of the equivalent ellipse $\mathrm{E}^{\mathrm{r}}$, equal to $A, s_{s}$ is the area of the regarding equivalent ellipse $\mathrm{E}^{\mathrm{s}}$, different from the size of the patch; $I_{x}^{s}$ and $I_{y}^{s}$ are the moments of inertia about the major and minor axes of ellipse $\mathrm{E}^{\mathrm{s}}$ (identical to ( $I_{2}$ $200, I_{1}$ ) those of the patch (Eq. 8) correspondingly); and $I_{x}^{r}$ and $I_{y}^{r}$ are the moments of inertia about the major axis and minor axis of ellipse $\mathrm{E}^{\mathrm{r}}$ respectively. The semi-major and semi-minor axes of $\mathrm{E}^{\mathrm{r}}$ (Eq. 16, 17) can be deduced from Eq. 9-15:

$$
\begin{aligned}
& \text { and } b_{r}=\sqrt{\frac{s_{r}}{\pi}} \sqrt[4]{\frac{I_{r}^{s}}{\pi}} \sqrt[4]{\frac{I_{y}^{s}}{I_{x}^{s}}}, \\
& \text {. }
\end{aligned}
$$

205Substituting $I_{y}^{s}, I_{x}^{s}$ with $I_{1}$ and $I_{2}$ respectively, and $S_{r} \quad$ with $A$ in Eq. 16-17, we finally get an expression for $E R$.

$$
E R=\frac{b_{r}}{a_{r}}=\sqrt{\frac{I_{2}}{I_{1}}}
$$

The ratio between the minor axis and the major axis of an equivalent ellipse, which has the same area and centroid as the patch, is used to define the index of 210 eccentric rate $(E R) . E R(0<E R \leq 1)$ represents the degree of patch's elongation along the major principal axis, and therefore reflects the patch's anisotropy in both major and minor principal axes. Values of $E R$ close to one indicate a patch is isotropic (I.e., nearly circular) while lower values of $E R$ indicate increasing patch 
anisotropy.

215 Caveats

The indices are generally useful for the analysis of most irregular patch shapes, but as noted above they are not useful for approximately circular patches. Similarly, they do not provide useful information for $U$ shaped patches. Further, it is apparent from Eq. 6 that the centroid of a patch is inversely proportional to the area of the 220 patch (area being the denominator in the equation). $P O$ and $V P O$ therefore are sensitive to point coordinate data errors on the patch's boundary, especially the smaller patches. This causes the effectiveness of $P O$ and $V P O$ to be a function of the resolution of the landscape image (I.e., they are useful only for large features in low resolution images).

\section{Study area and data source}

Qian-an county lies in the northwest of Jilin Province in China (Fig. 4), located at $44^{\circ} 38^{\prime} 10^{\prime \prime}-45^{\circ} 18^{\prime} 57^{\prime \prime} \mathrm{N}, 123^{\circ} 25^{\prime} 28^{\prime \prime}-124^{\circ} 22^{\prime} 48^{\prime \prime} \mathrm{E}, \quad$ with a total area of 3426.5 $\mathrm{km}^{2}$ and a population of 2.85 million. The climate is characterized as temperate semiarid continental monsoon. The annual average temperature is $6.4^{\circ} \mathrm{C}$. The frost-

230 free period is about 151 days. Annual precipitation is only $292 \mathrm{~mm}$, with $80 \%$ of the year's precipitation occurring from Jun to Sept, but the annual evaporation is 1874 $\mathrm{mm}$, so the evaporation greatly exceeds the precipitation. Wind, especially the strongly prevailing wind in winter from Northwest to Southeast plays an important role in shaping some local landscapes, as for most of the year, the weather is 235 extremely dry and the soil is sandy and uncovered (Qiu, 1991; Lu, 2000).

There are 90 lakes, known as "Qian-an Group Lakes", in the study area, with a total area up to 14903.89 ha. The lakes are typically small, and the water in the lakes is salty, seasonal and shallow, commonly about 1-2 m deep. The lakes are mostly in the shape of a raindrop, with gently sloping lake beds in each lake's northwest (the 240 windward side), and a steeply sloping lake beds in the southeast (the down wind side) with dune or loess piling up on this side. Wind is considered to be one of the most important forces driving the pattern formation of the lakes, I.e. The current shape of the lakes is the result of windy erosion upon the tectonic basins (Qiu, 1991; $\mathrm{Lu}, 2000)$.

245 Vector-based data of the Qian-an Group Lakes (1:100 000 scale) is analyzed here. The data comes from the National Land Use/Cover Database (NLUCD), which was interpreted from remotely sensed images on 21 Sept 2000 (Landsat TM, 30×30 $\mathrm{m})$, and stored in Arcinfo coverages. The interpretation was based on "The Standard 
of Remote Sensing Interpretation of Land Resource Investigation of China” (Liu, 2501996). The overall accuracy of classification is over $85 \%$. For more detailed information about the interpretation, please see Liu (1996) and Liu et al. (2003). The lake patches analyzed here are the lake polygons extracted from the NLUCD.

\section{Results and Discussion}

The indices of patch orientation $(P O)$ of the lakes are computed, and a 255 histogram for the results is made (Fig. 5). From Fig. 5, it can be seen that $60 \%$ of patch orientations lie within $120^{\circ}-150^{\circ}$, I.e., the major patch orientation is from Southeast to Northwest or from Northwest to Southeast. Out of the range $\left(<120^{\circ}\right.$ or $>150^{\circ}$ ), the patch number in each class of the histogram is usually less than 6 . The statistical data about the number and area of patches and related ratios in each 260 orientation range is listed in Table 1.

The vectorized patch orientation (VPO) indices of the lakes are in Fig. 6(a), and a histogram for the results is also made (Fig. 6(b)) (where ${ }^{\varepsilon}=0,{ }^{\varepsilon}$ is the fussy value). The most common vectorized patch orientation is also from Southeast to Northwest, $120^{\circ}-150^{\circ}$. Out of the range $\left(<120^{\circ}\right.$ or $\left.>150^{\circ}\right)$, the number of patches in 265 each class of the histogram is also much fewer (usually less than 6). Table 2 gives the statistical data about the number and area of patches and related ratios in each vectorized orientation range. Note that $V P O^{\mathcal{E}} \quad=0$ identifies that $12(22 \%)$ out of the 54 patches with $P O$ 's between $120^{\circ}$ and $150^{\circ}$ are oriented in the opposite direction to the other 42

270 Table 3 lists the results of $V P O$ of patch types with $P O$ between $120^{\circ}$ and $150^{\circ}$, with $\mathcal{E}=0.10$. These patches are classified into two groups: non-positively oriented patches (NPOP) and positively oriented patches (POP) (from Southwest to Northeast arranged). From Table 3, we can see that Qian-an Group Lakes are mainly in Southeast to Northwest or Northwest to Southeast orientation and most these lakes 275(38 POP patches out of 54 with area up to $70.32 \%$ of all), are Southeast to Northwest vectorized orientated. These lakes are in the cuneiform or raindrop shape oriented with the rounded end in the Southeast and the tapered end in the Northwest.

The 12 patches that were formerly assigned as POP in Table 2 (where ${ }^{\varepsilon}=0$ ) are now all grouped into NPOP, I.e., none of them bears a positive direction. Also, 280 four lakes previously classified as having vectorized orientation between $120^{\circ}$ and $150^{\circ}$ are now classified as NPOP. The value of $\mathcal{E}$ chosen therefore affects the distribution of patches between POP and NPOP, and is chosen by trial and error depending on the landscape and the objective of the analysis. For Qian-an Group Lakes, ${ }^{\mathcal{E}}=0.10$ is found to be the proper threshold for distinguishing NPOP and 285POP patches, and all of the NPOP lakes are identified by $V P O^{\varepsilon}$

$=0.10$. 
The prevailing wind direction (from Northwest to Southeast) in winter of the study area is opposite to the most common vectorized patch orientation. The edges of the tectonic basins of the lakes are made of sand, and the edges of the lakes on the upwind (Northwest) side extend into the wind due to the erosion from the prevailing 290 wind, especially on the major principal axis where the erosion is the most severe. In the southeastern side of the lakes where trees are planted by human beings, however, the sand blown by wind from the northeastern side sedimentates (Qiu, 1991). This erosion and sediment of sand blown by the wind in respective ends of major principal axis of the lakes results in the raindrop shape of the lakes (Fig. 7). Fig. 8 295 shows a typical longitudinal profile along the major principal axis of Fig. 7, which shows that the slope of the bottom of the lake is less steep in the upwind side.

Energy and materials within the patches are transported from the northwestern side to the southeastern side by the strong prevailing winds, opposite to the positive direction $\left(V P O^{\mathcal{E}}=0.10\right)$. Soil nutrients are also blown by the wind from the upwind 300 side of the lake and are moved down to the downwind side. In most of the Qian-an Group lakes, finer sands are found in the soil on the lake's boundary, in conjunction with wetland vegetation communities such as Carex $s p$ and Phragmites sp. These are often located on the downwind side of the lakes. However, in the upwind side, ground surfaces are usually covered by coarse sands and alkali soils, and almost no 305 vegetation grows in the waterside. An ecological gradient, therefore, clearly exists along the major principal axes of the lakes, and the $V P O^{\mathcal{E}}=0.10$ is an indirect measure of this.

Table 3 also shows that some of the lakes are non-positively oriented patches (NPOP). These lakes are orientated from Southeast to Northwest or from Northwest 310 to Southeast, but not a cuneiform shape. Without sand sedimentation caused by trees planted by humans on the downwind side, sand erosion in these lakes by the prevailing wind occurs both on the upwind side and on the downwind side. The shapes of the lakes elongated on both sides purely by the natural forces are therefore formed. The bottoms of these lakes are flat and the lakes are generally shallow and

315 therefore quicker to dry. The ecological environments of these lakes are poor compared to the cuneiform lakes, and therefore NPOP and POP lakes identified by $P O$ and $V P O$ are ecologically different.

The mean ER of the Qian-an Group lakes is 0.35, far less than 1. The major axes of the lakes are usually 2.85 (the reciprocal of mean $E R$ ) times the minor axes. This 320 indicates the lakes are generally elongated rather than circular. $E R$ and $P O$ indicate that the lake patches are highly anisotropic in Southeast to Northwest or Northwest to Southeast orientation. In the example of the Qian-an Group lakes therefore, the indices reveal a concurrence between patch orientation and prevailing wind direction and demonstrate quantitatively the factors driving anisotropy in the landscape. 


\section{Conclusions}

The exploration of vector analysis theory on landscape pattern (VATLP) commences with important planar properties defined in mechanics including centroid, moment of inertia, product of inertia and centroidal principal axes of a patch. Therefore, vector analysis theory on landscape pattern (VATLP) holds a solid 330 theoretical foundation in mechanics.

The establishment of VATLP makes it possible to realize vectorial characteristics (pattern shape in a certain orientation) of a landscape pattern. Pattern quantification based on this theory can be used to distinguish the anisotropy starting from patch level within a landscape.

335 The application of VATLP on Qian-an Group Lakes indicates that most lakes look like a raindrop and are arranged in a Southeast to Northwest orientation. This direction is just opposite to the prevailing wind direction in winter. The pattern formation of the lakes is closely related to the wind and some ecological processes associated with lake shape and orientation. Human land use such as tree planting

340 also plays in important role in the pattern formation (without there factor lakes are usually not cuneiform) and is revealed by VATLP indices. The measurement of VPO and $P O$ can reflect the pattern- formation processes induced by various driving forces, and $E R$ can quantify the anisotropic degree of the pattern. Wind is one of the most important forces driving the pattern formation of the Qian-an Group lakes (Qiu,

345 1991; Lu, 2000). The indices developed here reveal a concurrence between patch orientation and prevailing wind direction. They demonstrate quantitatively the factors driving anisotropy in the landscape, and indicate the existence of gradients that determine the ecological functioning of some of the lakes.

Here, VATLP not only successfully explained the formation mechanism of Qi'an 350 group lakes, but also distinguished artificial effects from natural ones. VATLP adds a new dimension to the landscape pattern metrics already available, many of which have been demonstrated to have substantial deficiencies when used to infer ecological function (Corry and Nassauer, 2005). According to Lausch and Herzog (2002), existing landscape metrics may be classified into four categories: "patch area 355 metrics", "edge and shape metrics", "diversity metrics" and "configuration metrics". None of these categories of metrics consider the orientation of patches, which is important to adequately describe the ecological function related to the landscape pattern. VATLP includes measures of direction that can assist in describing ecological function and thus represents a significant addition to existing landscape metrics.

360Acknowledgements

This research was jointly supported by the National Science Foundation of 
China (Grant No. 40371082), Fund of Key Laboratory of Ecological Restoration and Ecosystem Management of Jilin Province (Grant No. DS2004-03), and the Pioneer Field Project of Knowledge Innovation Program of CAS (Grant No. KZCX365 NA-3-15). We are grateful for the comments on the paper in paper reviewing by Dima Polevoy and Yuanzhi Zhang.

References

Ambrose, J.P., Bratton S.P., 1990. Trends in landscape heterogeneity along with the borders of Great Smoky Mountains National Park. Conserv. Boil. 4: 135-143.

370

Baker, W.J., Cai, Y., 1992. The r.le programs for multiscale analysis of landscape structure using GRASS geographical information system. Landscape Ecol. 7: 291-302.

Bailey, T.C., Gatrell, A.C., 1995. Interactive spatial data analysis. Longman Group Limited, Essex.

Csillag, F., Kabos, S., 2002. Wavelets, boundaries and the analysis of landscape pattern. Ecoscience 9: 177-190.

375 Chen, W.B., Xiao, D.N., Li, X.Z., 2002. Classification, application and creation of landscape indices. Journal of Applied Ecol. 13: 121-125. (in Chinese).

Cissel, J.H., Swanson, F.J., Weisberg, P.J., 1999. Landscape management using historical fire regimes: Blue River Oregon. Ecol. Appl. 9: 1217-1234.

Corry, R.C., Nassauer, J.I., 2005. Limitations of using landscape pattern indices to evaluate the $380 \quad$ ecological consequences of alternative plans and designs. Landscape and Urban Planning 72: -265-280.

Dorner, B., Lertzmann, K., Fall, J., 2002. Landscape pattern in topographically complex landscape: issues and techniques for analysis. Landscape Ecol. 17: 729-743.

Forman, R. T. T., Godron, M., 1986. Landscape Ecology. John Wiley and Sons, New York.

385 Fu, B., Chen L., Ma, K., Wang, Y., 2001. The Principle and Application of Landscape Ecology. Science Press, Beijing, China. (in Chinese).

Gustafson, E.J., Parker, G.R., 1992. Relationships between landscover proportion and indices of landscape spatial pattern. Landscape Ecol. 7: 101-110.

Gustafson, E.J., 1998. Quantifying landscape spatial pattern: What is the state of the art? $390 \quad$ Ecosystems 1: 143-156.

Gardner, R.H., O’Neill, R.V., 1991. Pattern, process and predictability: the use of neutral models 
for landscape analysis. In: Turner M.G. And Gardner R.H. (eds), Quantitative methods in landscape ecology. New York: Spring-Verlag. pp. 289-307.

Gardner, R.H., O’Neill, R.V., Turner, M.G., 1993. Ecological implications of landscape fragmentation. In: Pickett, S.T.A. McDonnell, M.J., (eds), Humans as Components of Ecosystems: Subtle Human Effects and the Ecology of Populated Areas. New York: SpringVerlag. pp. 208-226.

Gutzwiller, K.J., Anderson, S., 1992. Interception of moving organism: influences of patch shape, size, and orientation on community structure. Landscape Ecol. 6: 293-030.

400 Haines-Young, R., Chopping, M., 1996. Quantifying landscape structure: a review of landscape indices and their applications to forested landscapes. Prog. Phys. Geogr. 20: 418-445.

Hessburg, P.F., Smith B.G., Salter, P.B., 1999. Detecting change in forest spatial patterns from reference conditions. Ecol. Appl. 9: 1232-1252.

Imbernon, J., Branthomme, A., 2001. Characterization of landscape pattern of deforestation in tropical rain forests. Int. J. Remote Sens. 22:1753-1765.

Krummel, J.R., Gardner R.H., Sugihara G., O’Neill R.V., Coleman P.R., 1987. Landscape pattern in a disturbed environment. Oikos 48: 321-324.

Lausch, A., Herzog, F., 2002. Applicability of landscape metrics for the monitoring of landscape change: issues of scale, resolution and interpretability. Ecological Indicators 2: 3-15.

410 Legendre, P., Fortin, M.-J., 1989. Spatial pattern and ecological analysis. Vegetation 80: 107-138.

Lehmkuhl, J.F., Ruggiero, L.F., 1991. Forest fragmentation in the Pacific Northwest and its potential effects on wildlife. General Technical Report PNW-GTR-285. USDA Forest Service, Pacific Northwest Region, Portland, Oregon, USA.

Lehmkuhl, J.F., Heddburg P.F., Everett R.L., Huff M.H., Ottmar, R.D., 1994. Historical and 415 current forest landscapes of eastern Oregon and Washington. General Technical Report PNWGTR-328. USDA Forest Service, Pacific Northwest Region, Portland, Oregon, USA.

Li, X., Lu L., Cheng, G.D., Xiao, H.L., 2001. Quantifying landscape structure of the Heihe River basin, north-west China using Fragstats. Journal of Arid Environments 48: 521-535.

Li, B.L., Archer, S., 1997. Weighted mean patch size: a robust index for quantifying landscape 420 structure. Ecological Modeling 102: 353-361.

Li, B.L., Loehle, C., Malon, D., 1996. Microbial transport through heterogeneous porous media: random walk, fractal, and percolation approaches. Ecological Modeling 85: 285-302. 
Liu, J.Y., 1996. The Macro-scale survey and dynamic study of natural resources and environment of China by remote sensing. China Science and Technology Press, Beijing, China (in Chinese).

Liu, J.Y., Zhang, Z.X., Zhuang, D.F., 2003. A Study on the spatial- temporal dynamic changes of land-use and driving forces analyses of China in the 1990s', Geographical Research, 22, 1-12 (in Chinese).

Lu, J.F., Xiao R.H., Li Z.M., Leng X.T., Jie, D.M., 2000. The regional difference of type combination of lakes in the Songnen plain. Journal of Northeast Normal University. 32: 99-105. (in Chinese).

Milne, B.T., 1991. Lessons from applying fractal models to landscape patterns. In: Turner, M.G., Gardner, R.H., (eds), Quantitative methods in landscape ecology. New York: Spring-Verlag. 199-235.

435 Milne, B.T., 1992. Spatial aggregation and neutral models in fractal landscape. Am. Nat. 139: 32-57.

O’Neill, R.V., Riiters, K.H., Wickham, J.D., Jones, K.B., 1999. Landscape pattern metrics and regional assessment, Ecosyst. Health 5: 225- 233.

O’Neill, R.V., Krummel, J.R., Gardner, R.H., Sugihara, G., Jackson, B., DeAngelis, D.L., Turner, M.G., Zygmunt, B., Christensen, S.W., Dale, V.H., Graham, R.L., 1988. Indices of landscape pattern. Landscape Ecol. 1: 153-162.

McCarigal, K., Marks, B.J., 1995: FRAGSTATS: spatial pattern analysis program for quantifying landscape structure. US Department of Agriculture, Forest Service, General Technical Report PNW-GTR-351.

McCarigal, K., Cushman, S.A., Neel, M.C., Ene, E., 2002: FRAGSTATS: Spatial pattern 445 analysis program for categorical maps, version 3.0. University of Massachusetts, Amherst, Massachusetts.

Plotnick, R.E., Gardner, R.H., O’Neill, R.V., 1993. Lacunarity indices as measures of landscape texture. Landscape Ecol. 8: 201-211.

Pielou, E.C., 1997. Mathematical Ecology. Wiley, New York.

450 Qiu, S.W., 1991. Genesis of lakes and environmental changes in the Songnen plain. In: Qiu, S.W., (eds). Formation and Evolution of Natural Environment of Quaternary in Northeast Plain of China. Harbin Map Publishing House. pp. 146-154. (in Chinese).

Remmel, T.K., Csillag, F., 2003. When are two landscape pattern indices significantly different. J. Geograph. Syst. 5:331-351. 
455 Riitters, K.H., O’Neill, R.V., Hunsaker, C.T., Wickham, J.D., Yankee, D.H., Timmins, S., Jones, K.B., Jackson, B.L., 1995. A factor analysis of landscape pattern and structure metrics. Landscape Ecol. 10:23-39.

Rossi, R.E., 1992. Geostatistical tools for modeling and interpreting spatial dependence. Ecol. Monogr. 62: 277-314.

460 Tanner, J., 2003. Patch shape and orientation influences on seagrass epifauna are mediated by dispersal abilities. Oikos 100: 517-524.

Timoshenko, S.P., Gere, M.J., 1978. Mechanics of Materials. Van Nostrand Reinhold Company Ltd., Molly Millars Lane, Workingham, Berkshire, England.

Tischendorf, L., 2001. Can landscape indices predict ecological processes consistently? Landscape Ecol. 16: 235-254.

Trani, M.K., Giles, R.H., 1999. An analysis of deforestation: metrics used to describe pattern change. Forest Ecol. Manag. 114:459-470.

Turner, M.G., 1989. Landscape Ecology: The effect of pattern on process. Annual Review of Ecol Syst 20: 171-197.

470 Turner, M.G., Gardner, R.H., 1991. Quantitative Methods in Landscape Ecology. SpringerVerlag New York. ISBN: 0-387-94241-6.

Wu, J.G., 2000. Landscape Ecology Pattern, Process, Scale and Hierarchy. Beijing: Higher Education Press. pp. 158-163. (in Chinese). 